\title{
Identifying specific needs in adult cystic fibrosis patients: a pilot study using a custom questionnaire
}

\author{
Sandra Dury ${ }^{1,2^{*}}$, Jeanne-Marie Perotin ${ }^{1,3}$, Bruno Ravoninjatovo ${ }^{1}$, Catherine Llerena ${ }^{4}$, Julien Ancel ${ }^{1}$, \\ Pauline Mulette ${ }^{1}$, Muriel Griffon ${ }^{1}$, Sophie Carré ${ }^{1}$, Amélie Perrin ${ }^{5}$, François Lebargy ${ }^{1,2}$, Gaëtan Deslée $e^{1,3}$ and \\ Claire Launois $^{1}$
}

\begin{abstract}
Background: Adult patients with cystic fibrosis (CF) experience daily physical symptoms and disabilities that can be challenging to address for health care teams.

Methods: We sought to identify the most frequent topics that CF adults need to discuss with health care teams using a custom questionnaire including 62 items.

Results: Fifty patients were included, $70 \%$ men, mean age 27.6 years, with a mean body mass index of $21.8 \mathrm{~kg} / \mathrm{m}^{2}$. Mean FEV $1 \%$ was $64 \%$ of predicted value. Forty-two percent of patients selected at least one topic. The most frequently selected topics were fatigue (20\%), professional or scholar worries (18\%), procreation (16\%), physical activities $(16 \%)$ and evolution of CF disease (16\%). Women were more frequently concerned about fatigue, procreation and profession/school.
\end{abstract}

Conclusions: Using a custom questionnaire, we identified that CF adults express various unmet needs that extend beyond usual respiratory and nutritional concerns or treatment adherence. The interest of this questionnaire by health care team for improving therapeutic management of CF patients remains to be validated.

Trial registration: The study was registered on ClinicalTrials.gov (NCT02924818) on 5th October 2016.

Keywords: Cystic fibrosis, Needs, Questionnaire, Quality of life, Fatigue

\section{Background}

Cystic fibrosis (CF) is the most common life-threatening genetic disease in the USA and Caucasian populations. CF prognosis depends primarily on chronic respiratory failure and malnutrition, which are the focus of attention during follow-up visits $[1,2]$. Thanks to advances in pharmacological treatments and improvements in patients

\footnotetext{
*Correspondence: sdury@chu-reims.fr

${ }^{1}$ Department of Respiratory Diseases, Reims University Hospital, Maison Blanche University Hospital, 45, rue de Cognacq-Jay, 51092 Reims cedex France

Full list of author information is available at the end of the article
}

care, CF patients' survival dramatically increased. The median predicted survival for USA CF patients born in 2019 was 48.4 years [3].

Consequently, health care teams will need to serve a growing population of adults living with $\mathrm{CF}$ as a chronic illness. CF adults experience daily physical symptoms (cough, shortness of breath, lack of energy, nasal discharge) that significantly impair their functional status and quality of life $[4,5]$. Patients also suffer from psychological symptoms including anxiety, irritability, sleeping troubles and sadness [4].

A few studies analysed expectations and unmet needs of CF adult patients. Sawicki et al. [6] reported that 
one-third of 18-24 years old CF patients required information about "ways to deal with decreased energy", "new CF therapies", and "ways to deal with the unpredictability of the future". In a recent survey, CF patients reported a high level of confidence in their abilities in nutritional care and the role of enzymes in CF therapy but a low confidence in mental health and ability to have children [7]. Interestingly, CF patients have significant unmeet existential needs that are most prevalent in patients with higher symptom burden [8]. As part of a multidisciplinary evaluation, health care teams involved in CF management should not exclusively consider usual indicators of disease severity (e.g., lung function, body mass index, exercise performance and pulmonary exacerbations) to evaluate CF patients [9].

The objective of our study was to identify the most frequent topics that $\mathrm{CF}$ adults need to discuss with health care team during regular visits. We used an individual educational custom questionnaire available for French health care teams since 2013 [10]. This tool consists in a list of predefined topics covering the main domains of social, professional, familial and sexual life, psychological feeling, symptoms related to CF, daily life organisation, hobbies, treatments and life project.

\section{Methods}

\section{Study protocol}

CF adult patients were prospectively recruited from the University Hospital of Reims-Department of Respiratory Diseases between November 2016 and December 2019. Patients were included in the RINNOPARI study (Recherche et INNOvation en PAthologie Respiratoire Inflammatoire), an observational cohort of inflammatory chronic lung diseases. The study was approved by the Ethics Committee of Dijon EST I on 31rd October 2016 (N 2016-A00242-49) and by the French National Agency for Medicines and Health Products (ANSM) on 25th April 2016. The protocol was registered on ClinicalTrials. gov (NCT02924818) on 5th October 2016. Each patient signed a written informed consent form. All methods including recruitment, data collection and analysis have been performed in accordance with the declaration of Helsinki.

All participants were recruited for a regular CF care visit. Patients were included if they were at least 18 years of age. Exclusion criteria were previous or planned lung transplantation and patients requiring an urgent visit. Anonymised collected data included demography, clinical characteristics, pulmonary function tests results and sputum microbiological data. Quality of life was evaluated using the St George's Respiratory Questionnaire (SGRQ) assessing symptoms and impact on daily activities (a maximum of 100 score indicates maximum impairment of quality of life) [11]. Chronic infection by Pseudomonas aeruginosa, and by extension chronic infection by Staphylococcus aureus, Stenotrophomonas maltophilia or Achromobacter xylosoxidans was defined according to Leeds criteria [12].

\section{Unmet needs questionnaire}

"Des mots pour le dire" (literally "Words to say it") is an individual educational questionnaire available since 2013 in French language. This questionnaire was developed by the workshop GETHEM (Groupe Education THErapeutique et Mucoviscidose) in order to improve medical visits by identifying CF patient needs [10]. This structured $\mathrm{CF}$-specific questionnaire focuses on symptoms and feelings than are infrequently assessed during usual medical visit, including treatment burden, impact of illness on daily life and personal projects. The questionnaire consists of a list of 62 predefined topics divided in nine domains: social and familial life, professional life, sexual life, psychological feeling, symptoms related to CF, daily life, hobbies, treatments and projects. It also includes an open-ended question regarding items judged as irrelevant and too frequently raised during visits.

Included patients were asked to complete the questionnaire just before a visit by selecting the topics they need to discuss during the medical visit and circle the three most important topics to address.

\section{Statistical analysis}

Data were described as numbers (percentages) or mean \pm standard deviation or median [interquantile range] depending on distribution. Differences in clinical characteristics were assessed using chi-square tests or Fisher's exact tests, as appropriate, for qualitative variables, and Student t-tests or Mann-Whitney U-tests for quantitative variables. A $p$ value $<0.05$ was considered statistically significant. Results were analysed with SPSSv26.

\section{Results}

Fifty-one consecutive CF patients were included in the study. One patient was excluded because of previous lung transplantation. Fifty patients were analysed. No patient declined the study.

\section{Patients characteristics}

Demographic and clinical characteristics of patients are detailed in Table 1 . Briefly, patients were mostly men (70\%), mean aged $27.6 \pm 8.7$ years with a mean body mass index of $21.8 \pm 3.3 \mathrm{~kg} / \mathrm{m}^{2}$. Two third were employed and or student, $67.3 \%$ lived as a couple. A medical history of depression was present in $15.7 \%$ of CF-patients. 
Table 1 Demographic and Clinical Characteristics

\begin{tabular}{ll}
\hline Variables & \\
\hline Male & $35(70 \%)$ \\
Age (years) & $27.6 \pm 8.7$ \\
BMl (kg/m $\left.{ }^{2}\right)$ & $21.8 \pm 3.3$ \\
Smoker & $5(9.8 \%)$ \\
Employment status & \\
Student & $14(27.4 \%)$ \\
Working & $25(49.0 \%)$ \\
None & $16(32.0 \%)$ \\
Family status & \\
Maried/cohabiting & $33(67.3 \%)$ \\
Living with their parents & $16(32.6 \%)$ \\
Comorbid illnesses & \\
Pancreatic insufficiency & $40(80.0 \%)$ \\
Diabetes & $17(34.0 \%)$ \\
Depression & $8(15.7 \%)$ \\
Symptoms & \\
Chronic cough & $40(80.0 \%)$ \\
Chronic expectoration & $45(90.0 \%)$ \\
Dyspnea & $26(52.0 \%)$ \\
Exacerbation in the last year & $35(70.0 \%)$ \\
Number of episodes per patient & $2.3 \pm 1.4$ \\
SGRQ & \\
Impact & $25.5 \pm 17.3$ \\
Activity & $19.7 \pm 15.8$ \\
Symptoms & $33.8 \pm 21.0$ \\
Data are & $45.0 \pm 20.6$ \\
\hline
\end{tabular}

Data are expressed as frequency (percentage), mean \pm standard deviation or median (Interquartile range)

$B M I$ body mass index, SGRQ St George's Respiratory Questionnaire

The mean SGRQ score was $25.5 \pm 17.3$ with a predominant impairment in the symptoms domain $(45 \pm 20.6)$. Seventy percent of the patients presented at least one respiratory exacerbation in the previous year, with a mean of $2.3 \pm 1.4$ events/patient/year.

Spirometric and microbiological data are detailed in Table 2. Mean $\mathrm{FEV}_{1} \%$ was $64 \pm 30 \%$ of predicted value. Chronic infection by Staphylococcus aureus and Pseudomonas aeruginosa were present in $74 \%$ and $40 \%$ of the patients, respectively.

\section{Unmet needs}

Twenty-four patients (48\%) did not express any unmet needs (Table 3). There was no significant difference in baseline characteristics between patients selecting at least one unmet need and those who did not. Patients selected a median of 1 [4.75] topics, twenty-six patients (52\%) indicated at least one topic; five patients selected more than 10 topics. The most frequently selected topics were "fatigue" (20\%), "study or job" (18\%), "ability to
Table 2 Lung function and microbiology data

\begin{tabular}{|c|c|}
\hline Variables & \\
\hline \multicolumn{2}{|l|}{ Spirometry } \\
\hline $\mathrm{FEV}_{1}, \%$ predicted & $64 \pm 30$ \\
\hline \multicolumn{2}{|l|}{ 6-Min walk distance } \\
\hline Distance, $m$ & $562 \pm 86$ \\
\hline Minimal saturation, \% & $92 \pm 7$ \\
\hline \multicolumn{2}{|l|}{ Blood gases on air } \\
\hline $\mathrm{PaO}_{2}, \mathrm{mmHg}$ & $87 \pm 20$ \\
\hline $\mathrm{PaCO}_{2}, \mathrm{mmHg}$ & $39 \pm 5$ \\
\hline \multicolumn{2}{|l|}{ Chronic colonisation } \\
\hline Pseudomonas aeruginosa & $20(40.0 \%)$ \\
\hline Staphylococcus aureus & $37(74.0 \%)$ \\
\hline Achromobacter xylosoxidans & $2(4.0 \%)$ \\
\hline Stenotrophomonas maltophilia & $1(2.0 \%)$ \\
\hline \multicolumn{2}{|c|}{ Microbiological data at inclusion ( $n=42$, sputum) } \\
\hline Pseudomonas aeruginosa & $17(40.5 \%)$ \\
\hline Staphylococcus aureus & $32(76.2 \%)$ \\
\hline Achromobacter xylosoxidans & $1(2.4 \%)$ \\
\hline
\end{tabular}

Data are expressed as frequency (percentage) or mean \pm standard deviation

FEV ${ }_{1}$ forced expiratory volume at first second

conceive a child" (16\%), "physical activity and sports" (16\%) and "disease evolution" (16\%). A lower number of patients reported "cough" (12\%), "medical advances" (12\%), "mood" (12\%), several aspects of daily life organization ("leisure activity" (10\%), "trip abroad" (8\%)) and "personal projects" (8\%) or "professional projects" (10\%).

Patients were asked to circle up to 3 most important items among those selected. Only 17 among 50 patients (34\%) selected at least one most important item. A total of 28 "most important" topics were selected, including fatigue $(n=4)$ and ability to conceive a child $(n=4)$. Domains of professional and psychological life as well as therapeutic management were also identified. Only three patients thought that some topics covered by the health care team were irrelevant and too frequently discussed (sport $\mathrm{n}=1$, shopping/housework $\mathrm{n}=1$, usual treatment $\mathrm{n}=1$ ). No patient wished to consider an issue other than those given in the questionnaire.

We next analysed patients' characteristics depending on the 5 most frequently selected topics (Table 4). When compared to men, women were more frequently concerned about procreation (33\% of women vs $9 \%$ of men, $p=0.03$ ), study or job ( $40 \%$ of women vs $9 \%$ of men, $p=0.008)$ and fatigue ( $47 \%$ of women vs $9 \%$ of men, $p=0.002$ ). In addition, patients concerned by study or job tended to be younger $(22.6 \pm 4.5$ vs $28.5 \pm 8.7$ years, $p=0.054)$ and more than half suffered from diabetes ( $54 \%$ vs $10 \%, p=0.022$ ). Fatigue was selected by patients with a significantly more impaired quality of life (SGRQ 
Table 3 Unmet needs

\begin{tabular}{|c|c|c|c|c|}
\hline \multirow{2}{*}{$\begin{array}{l}\text { Domains } \\
\text { Social and familial life }\end{array}$} & \multicolumn{2}{|c|}{$\begin{array}{l}\text { Requested } \\
\text { domains }\end{array}$} & \multicolumn{2}{|c|}{$\begin{array}{l}\text { Prime } \\
\text { domains }\end{array}$} \\
\hline & & & & \\
\hline Family & 2 & $4.0 \%$ & 0 & $0.0 \%$ \\
\hline Couple & 3 & $6.0 \%$ & 0 & $0.0 \%$ \\
\hline Children & 2 & $4.0 \%$ & 0 & $0.0 \%$ \\
\hline Friends & 3 & $6.0 \%$ & 0 & $0.0 \%$ \\
\hline Romantic encounter & 1 & $2.0 \%$ & 0 & $0.0 \%$ \\
\hline Risky driving & 2 & $4.0 \%$ & 0 & $0.0 \%$ \\
\hline To have a child & 8 & $16.0 \%$ & 4 & $8.0 \%$ \\
\hline To discuss of specific illness & 1 & $2.0 \%$ & 0 & $0.0 \%$ \\
\hline \multicolumn{5}{|l|}{ Professional life } \\
\hline Study/job & 9 & $18.0 \%$ & 2 & $4.0 \%$ \\
\hline Internship abroad & 1 & $2.0 \%$ & 1 & $2.0 \%$ \\
\hline Sick leave & 2 & $4.0 \%$ & 1 & $2.0 \%$ \\
\hline Social rights & 2 & $4.0 \%$ & 1 & $2.0 \%$ \\
\hline Revenues & 3 & $6.0 \%$ & 0 & $0.0 \%$ \\
\hline Mutual insurances & 4 & $8.0 \%$ & 2 & $4.0 \%$ \\
\hline Transports & 3 & $6.0 \%$ & 0 & $0.0 \%$ \\
\hline \multicolumn{5}{|l|}{ Sexual life } \\
\hline Libido & 4 & $8.0 \%$ & 0 & $0.0 \%$ \\
\hline Body image & 3 & $6.0 \%$ & 0 & $0.0 \%$ \\
\hline Shortness of breath & 4 & $8.0 \%$ & 0 & $0.0 \%$ \\
\hline Contraception & 1 & $2.0 \%$ & 0 & $0.0 \%$ \\
\hline Comfortable positions & 0 & $0.0 \%$ & 0 & $0.0 \%$ \\
\hline Venereal disease & 0 & $0.0 \%$ & 0 & $0.0 \%$ \\
\hline Pain & 1 & $2.0 \%$ & 0 & $0.0 \%$ \\
\hline \multicolumn{5}{|l|}{ Psychological feeling } \\
\hline Mood & 6 & $12.0 \%$ & 1 & $2.0 \%$ \\
\hline Self-worth & 2 & $4.0 \%$ & 1 & $2.0 \%$ \\
\hline Self-efficacy & 2 & $4.0 \%$ & 0 & $0.0 \%$ \\
\hline Motivation & 3 & $8.0 \%$ & 1 & $2.0 \%$ \\
\hline Anxiety & 2 & $4.0 \%$ & 0 & $0.0 \%$ \\
\hline Lose interest & 3 & $6.0 \%$ & 1 & $2.0 \%$ \\
\hline \multicolumn{5}{|c|}{ Symptoms related to the specific disease } \\
\hline Pains & 2 & $4.0 \%$ & 0 & $0.0 \%$ \\
\hline Fatigue & 10 & $20.0 \%$ & 4 & $8.0 \%$ \\
\hline Sleep quality & 2 & $4.0 \%$ & 1 & $2.0 \%$ \\
\hline Bladder weakness & 1 & $2.0 \%$ & 0 & $0.0 \%$ \\
\hline Digestive gases & 1 & $2.0 \%$ & 0 & $0.0 \%$ \\
\hline Smelly stool odour & 1 & $2.0 \%$ & 0 & $0.0 \%$ \\
\hline constipation/diarrhea & 4 & $8.0 \%$ & 1 & $2.0 \%$ \\
\hline Cough & 6 & $12.0 \%$ & 0 & $0.0 \%$ \\
\hline Sputum & 3 & $6.0 \%$ & 0 & $0.0 \%$ \\
\hline Mycosis & 1 & $2.0 \%$ & 1 & $2.0 \%$ \\
\hline \multicolumn{5}{|l|}{ Daily life organisation } \\
\hline Daily shopping/housework & 3 & $6.0 \%$ & 0 & $0.0 \%$ \\
\hline Rest time & 1 & $2.0 \%$ & 1 & $2.0 \%$ \\
\hline Planning of occupations/nursing & 1 & $2.0 \%$ & 0 & $0.0 \%$ \\
\hline Hygiene & 2 & $4.0 \%$ & 0 & $0.0 \%$ \\
\hline Self-sufficiency & 3 & $6.0 \%$ & 1 & $2.0 \%$ \\
\hline
\end{tabular}

Table 3 (continued)

\begin{tabular}{|c|c|c|c|c|}
\hline \multirow{2}{*}{$\begin{array}{l}\text { Domains } \\
\text { Eating times }\end{array}$} & \multicolumn{2}{|c|}{$\begin{array}{l}\text { Requested } \\
\text { domains }\end{array}$} & \multicolumn{2}{|c|}{$\begin{array}{l}\text { Prime } \\
\text { domains }\end{array}$} \\
\hline & 2 & $4.0 \%$ & 0 & $0.0 \%$ \\
\hline \multicolumn{5}{|l|}{ Leisure } \\
\hline Leisure activity & 5 & $10.0 \%$ & 1 & $2.0 \%$ \\
\hline Sports & 8 & $16.0 \%$ & 1 & $2.0 \%$ \\
\hline Costs & 2 & $4.0 \%$ & 0 & $0.0 \%$ \\
\hline Holidays & 3 & $6.0 \%$ & 0 & $0.0 \%$ \\
\hline Vacation abroad & 4 & $8.0 \%$ & 1 & $2.0 \%$ \\
\hline \multicolumn{5}{|l|}{ Treatments } \\
\hline Regularity & 4 & $8.0 \%$ & 2 & $4.0 \%$ \\
\hline Interruption & 1 & $2.0 \%$ & 0 & $0.0 \%$ \\
\hline Limitation & 1 & $2.0 \%$ & 0 & $0.0 \%$ \\
\hline Logistical supports/supply & 1 & $2.0 \%$ & 0 & $0.0 \%$ \\
\hline Efficacy & 1 & $2.0 \%$ & 1 & $2.0 \%$ \\
\hline Side effects & 4 & $8.0 \%$ & 1 & $2.0 \%$ \\
\hline Disease evolution/future & 8 & $16.0 \%$ & 2 & $4.0 \%$ \\
\hline Fertility treatment & 3 & $6.0 \%$ & 2 & $4.0 \%$ \\
\hline Transplantation & 3 & $6.0 \%$ & 1 & $2.0 \%$ \\
\hline Medical advances/research & 6 & $12.0 \%$ & 3 & $6.0 \%$ \\
\hline \multicolumn{5}{|l|}{ Project } \\
\hline Personal & 4 & $8.0 \%$ & 1 & $2.0 \%$ \\
\hline Professional & 5 & $10.0 \%$ & 1 & $2.0 \%$ \\
\hline Other & 1 & $2.0 \%$ & 0 & $0.0 \%$ \\
\hline None domains marked & 24 & $48.0 \%$ & & \\
\hline \multicolumn{5}{|c|}{ Domains considered to be unnecessary or repetitive } \\
\hline Sports & 1 & $2.0 \%$ & & \\
\hline Shopping/housework & 1 & $2.0 \%$ & & \\
\hline Usual treatments & 1 & $2.0 \%$ & & \\
\hline
\end{tabular}

Data are expressed as frequency (percentage)

total score: $37.2 \pm 15.9$ vs $22.3 \pm 16.4, p=0.014$; SGRQ activity score: $45.2 \pm 23.2$ vs $30.3 \pm 19.3, p=0.048$ ).

\section{Discussion}

Using an individual simple questionnaire, we identified a number of various topics designated by patients to be discussed with health care team. Even if some topics of this questionnaire such as cough or fatigue are frequently assessed in CF, many topics appeared different from the topics addressed during regular visits usually focusing on life threatening complications like chronic respiratory failure and malnutrition.

More than half of the patients indicated at least one topic with $10 \%$ selecting more than 10 topics, highlighting frequent uncovered needs during regular follow-up visits. A few previous studies investigated CF specific needs and association with clinical characteristics [6-8, 13, 14]. Those studies used questionnaires filled during a follow-up visit or sent by mail and mainly focused on medical topics $[6,7]$. Despite differences in methods, our 


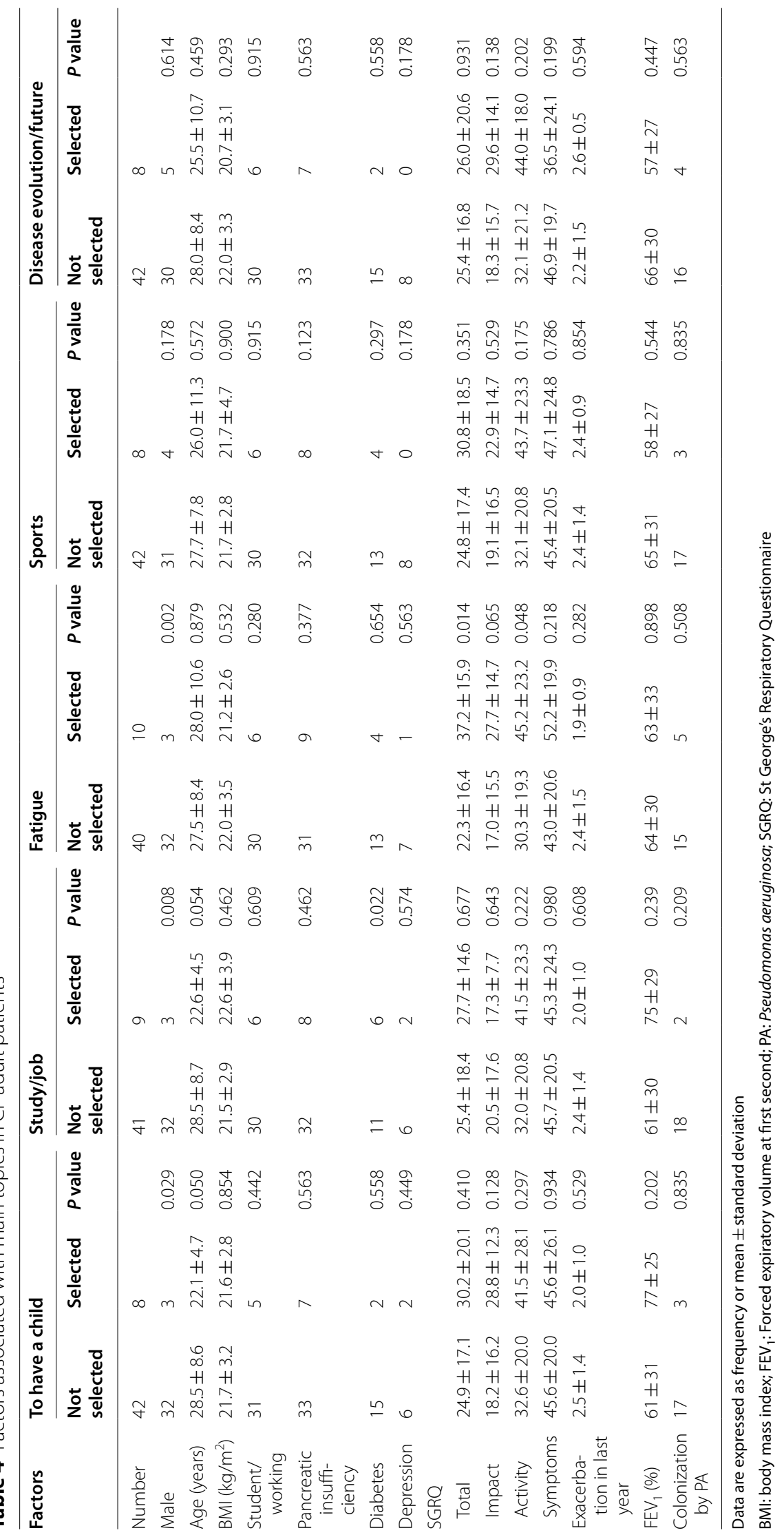


study confirmed some previously identified unmet needs: Sawicki et al. [6] described the most frequent unmet needs as "decreased energy" (32\%), "new CF therapies" (31\%), "unpredictability of the future" (28\%), "CF worsening" (27\%) and "medication side effects" (27\%). Fatigue is a very frequent symptom in CF, considered as moderate to severe in $56 \%$ of cases [8]. Its associations with clinical and functional patients' characteristics is controversial but its impact on health status has been showed $[15,16]$. In our study, we identified a clear association between fatigue as an unmet need and quality of life impairment, highlighting the importance fatigue screening.

Information about procreation was frequently selected, especially by female and youngest patients. Previous survey identified information about procreation as a need for CF patients [6, 7]. Patients' need for discussion about procreation should be periodically assessed during visits and not restricted to urgent need expressed by patients facing this issue. Another major unmet topic to discuss raised by this study is the difficulties encountered in studies or professional activities. Patients' employment status in our study was similar to the Cystic Fibrosis Foundation Patient Registry with $70 \%$ of student or working patients [3]. In our study, professional or scholar worries were not associated with employment status. CF can have important impact on professional life. Previous studies reported that $40 \%$ of CF patients quit their job because of the disease, $47 \%$ declared that CF affected their career choice, $24 \%$ changed duties and $23 \%$ suffered from workplace discrimination [17]. Surprisingly, in a cohort of 73 patients diagnosed with CF after 18 years, the item of employment/insurance was considered as of moderate interest [13]. In our study, more than half of the patients who were concerned about study or job suffered from diabetes. Quality of life has been shown to be significantly impaired in CF-related diabetes, especially when requiring insulin [18]. Our results suggest that CF-related diabetes may also be associated with more concerns regarding study or job. To our knowledge, the impact of CF-related diabetes on professional activity or studies has not been previously evaluated, justifying additional studies in this field.

Our study highlighted very different needs among CF adult population. Half of patients expressed no specific needs. Those patients were not different regarding demographical, clinical and functional characteristics. Lack of responses may reflect either a lack of interest (however, no patient declined the study) or absence of unmet management needs. It should also be pointed out that identified unmet needs are very disparate. Indeed, sixty items among the 62 proposed have been selected at least once. In the study of Obregon et al. [14], none of the main unmet supportive care needs (anxiety, sadness, pain and worries about the future) were associated with pulmonary impairment, BMI and pulmonary exacerbation in prior year but with age, income and or religion. Given the absence of associations between CF phenotype and patient needs, a systematic use of an educational questionnaire during follow-up visits could help to identify unmet needs.

Some topics were rarely selected in our study. Patients considered themselves as well-informed regarding treatment (interruption, limitation, logistical supports/supply, efficacy) and daily life organization. CF patients usually report a high level of confidence in their abilities in nutritional care and role of enzymes in CF therapy [7]. Sawicki et al. [6] reported that the needs in information regarding advance care planning, lung transplant, genetics, and nutrition were low. We can speculate that needs may have changed over time. Thirty years ago, most of patients reported that problems related to daily life with CF were not discussed [19]. Patients may be reluctant to approach concerns related to sexual life. None of the previous studies about expectations of CF patients analyzed this topic $[4,6-8,13]$. In a recent study, only one-third of interprofessional CF providers (physicians, nurses, social workers and other disciplines) reported being comfortable with sexual and reproductive health for adolescent and young adult women [20]. A majority of women confirmed never receiving or discussing sexual and reproductive health care with their CF team [21].

There are limitations to our study. First, our sample size is relatively small which could limit the generalizability of our results. However, clinical and functional characteristics of our cohort were similar to other studies regarding BMI [22], prevalence of exocrine pancreatic insufficiency [23], diabetes [24], Pseudomonas aeruginosa infections [12] and $\mathrm{FEV}_{1}$ [25]. Second, the questionnaire developed by a therapeutic education group has not been evaluated yet, and our study has to be considered as a pilot exploratory study. Of note previous studies have also used or modified some questionnaires not validated in CF and developed in other diseases such as cancer [4, 8, 14]. Finally, we have not assessed if the specific needs identified by this questionnaire led to a specific management. It would be interesting to analyse the impact of this custom questionnaire on therapeutic management of CF patients in a larger cohort.

\section{Conclusions}

This study highlights that needs of CF adult patients extend beyond respiratory, nutritional concerns and treatment adherence. Despite frequent follow-up visits, half patients are still awaiting to discuss many and various issues. They express in particular an on-going interest for medical problem such as fatigue, procreation 
and disease evolution but also for social and professional issues. Even if two third of patients have an employment status, our study shows a high level of worry about future. Health care team should periodically individually identify CF patients' needs and not neglect any issues. An individual educational questionnaire may help the health care team to identify specific needs in CF adults. However, the interest of this questionnaire by health care team for improving therapeutic management of CF patients remains to be validated.

\author{
Abbreviations \\ BMI: Body mass index; CF: Cystic fibrosis; FEV 1 : Forced expiratory volume \\ at first second; PA: Pseudomonas aeruginosa; SGRQ: St George's Respiratory \\ Questionnaire.
}

\section{Acknowledgements}

The authors thank the workshop GETHEM.

\section{Authors' contributions}

Substantial contributions to the conception: SD, BR, CLL, AP, GD, CLA. Design of the work: SD, BR, FL, GD, CLA. Acquisition and analysis of the data: SD, JMP, BR, CLL, JA, PM, MG, SC, AP. Drafting the work or substantively revising the manuscript: SD, JMP, BR, CLL, JA, PM, MG, SC, AP FL, GD, CLA. All authors have approved the submitted version and have agreed both to be personally accountable for the author's own contributions and to ensure that questions related to the accuracy or integrity of any part of the work, even ones in which the author was not personally involved, are appropriately investigated, resolved, and the resolution documented in the literature. All authors read and approved the final manuscript.

\section{Funding}

Reims University Hospital and Champagne Ardennes University (HospitalUniversity Project named RINNOPARI).

\section{Availability of data and materials}

The datasets used and/or analysed during the current study are available from the corresponding author on reasonable request.

\section{Declarations}

\section{Ethics approval and consent to participate}

The RINNOPARI (Recherche et INNOvation en PAthologie Respiratoire Inflammatoire) study was approved by the Ethics Committee of Dijon EST I on 31rd May 2016 (№2016-A00242-49) and by the French National Agency for Medicines and Health Products (ANSM) on 25th April 2016, and declared on ClinicalTrials.gov (NCT02924818) on 5th October 2016.

\section{Consent for publication}

Each patient signed a written informed consent.

\section{Competing interests}

SD reports reimbursements from Novartis and Boehringer Ingelheim, and personal fees from Chiesi outside the submitted work. BR reports reimbursements from Novartis, Mylan, Vertex, Vitalair and Reckitt Benckiser. CLL reports personal fees from Zambon outside the submitted work. MG reports reimbursements from Novartis and Zambon. SC reports reimbursements from Novartis and Vitalaire. FL reports reimbursements from Boehringer Ingelheim and personal fees from Novartis, Boehringer Ingelheim and GlaxoSmithKline outside the submitted work. GD reports personal fees from Nuvaira, AstraZeneca, Boehringer Ingelheim, Chiesi, BTG-PneumRx, and Novartis outside the submitted work.

\section{Author details}

${ }^{1}$ Department of Respiratory Diseases, Reims University Hospital, Maison Blanche University Hospital, 45, rue de Cognacq-Jay, 51092 Reims cedex, France. ${ }^{2}$ EA 4683 Medical and Pharmacological, University of Reims, Reims, France. ${ }^{3}$ INSERM UMRS 1250, Reims University Hospital, Reims, France. ${ }^{4}$ Department of Pediatrics, Grenoble University Hospital, Grenoble, France. ${ }^{5}$ Department of Pediatrics, Nantes University Hospital, Nantes, France.

Received: 22 February 2021 Accepted: 13 July 2021

Published online: 18 August 2021

References

1. Steinkamp G, Wiedemann B, on behalf of the german CFQA Group. Relationship between nutritional status and lung function in cystic fibrosis: cross sectional and longitudinal analysis from the German CF quality assurance (CFQA). Thorax. 2002;57:596-601.

2. Elborn JS. Cystic fibrosis. Lancet. 2016;388:2519-31.

3. US Cystic Fibrosis Registry (Cystic Fibrosis Foundation). Annual data report 2019. https://www.cff.org/Research/Researcher-Resources/Patie nt-Registry-Annual-Data-Report.pdf

4. Sawicki GS, Sellers DE, Robinson WM. Self-reported physical and psychological symptom burden in adults with cystic fibrosis. J Pain Symptom Manag. 2008;35(4):372-80.

5. Quittner AL, Goldbeck L, Abbott J, Duff A, Lambrecht P, Solé A, Tibosch MM, Bergsten brucefors A, Yüksel H, Catastini P, Blackwell L, Barker D. Prevalence of depression and anxiety in adults with cystic fibrosis and parent caregivers: results of The International Depression Epidemiological Study across nine countries. Thorax. 2014;69(12):1090-7.

6. Sawicki GS, Sellers DE, McGuffie K, Robinson W. Adults cystic fibrosis report important and unmet needs for disease information. J Cyst Fibros. 2007;6:411-6.

7. Lonabaugh KP, O'Neal KS, McIntosh H, Condren M. Cystic fibrosis-related education: are we meeting patient and caregiver expectations? Patient Educ Couns. 2018;101(10):1865-70. https://doi.org/10.1016/j.pec.2018.06. 004 (Epub 2018 Jun 9)

8. Trandel ET, Pilewski JM, Dellon EP, Moreines LT, Yabes JG, Jeong K, Kavalieratos D. Symptom burden and unmet existential needs in adults with cystic fibrosis. West J Nurs Res. 2019;41(10):1448-64.

9. Riekert KA, Bartlett SJ, Boyle MP, Krishnan JA, Rand CS. The association between depression, lung function, and health-related quality of life among adults with cystic fibrosis. Chest. 2007;132:231-7.

10. https://educationtherapeutique.muco-cftr.fr.

11. Padilla A, Olveira G, Olveira C, Dorado A, Plata AJ, Gaspar I, Pérez-Frias J. Validity and reliability of the St George's respiratory questionnaire in adults with cystic fibrosis. Arch Bronchoneumol. 2007;43(4):205-11.

12. Lee TWR, Brownlee KG, Conway SP, Denton M, Littelwood JM. Evaluation of a new definition for chronic Pseudomonas aeruginosa infection in cystic fibrosis patients. J Cyst Fibros. 2003;21(1):29-34.

13. Widerman E. Knowledge, interests and educational needs of adults diagnosed with cystic fibrosis after age 18. J Cyst Fibros. 2003;2:97-104.

14. Obregon LL, Jeong K, Hoydich ZP, Yabes J, Pilewski J, Richless C, Moreines LT, Dellon EP, Goss CH, Arnold RM, Kavalieratos D. Associations between demographic characteristics and unmet supportive care needs in adults with cystic fibrosis. BMJ Support Palliat Care 2019:14.

15. Nap-van der Vlist MM, Burghard M, Hulzebos HJ, Doeleman WR, Heijerman HGM, van der Ent CK, Nijhof SL. Prevalence of severe fatigue among adults with cystic fibrosis: a single center study. J Cyst Fibros. 2018;17:368-74.

16. Jarad NA, Sequeiros IM, Patel P, Bristow K, Sund Z. Fatigue in cystic fibrosis: a novel prospective study investigating subjective and objective factors associated with fatigue. Chron Respir Dis. 2012;9(4):241-9.

17. Targett K, Bourke S, Nash E, Murphy E, Ayres J, Devereux G. Employment in adults with cystic fibrosis. Occup Med. 2014;64:87-94.

18. Kwong E, Desai S, Chong L, Lee K, Zheng J, Wilcox PG, Quon BS. The impact of cystic fibrosis-related diabetes on health-related quality of life. J Cyst Fibros. 2019;18:734-6.

19. Hames A, Beesley J, Nelson R. Cystic fibrosis: what do patients know, and what else would they like to know? Respir Med. 1991;85:389-92. 
20. Kazmerski TM, Nelson EB, Newman LR, Haviland M, Luff D, Leichtner AM, Hayes MM, Miller E, Emans SJ, Sawicki GS. Interprofessional provider educational needs and preferences regarding the provision of sexual and reproductive health care in cystic fibrosis. J Cyst Fibros. 2019;18:671-6.

21. Kazmerski TM, Sawicki GS, Miller E, Jones KA, Abebe KZ, Tuchman LK, Ladores S, Rubenstein RC, Sagel SD, Weiner DJ, Pilewski JM, Orenstein DM, Borrero S. Sexual and reproductive health care utilization and preferences reported by young women in cystic fibrosis. J Cyst Fibros. 2018;17:64-70.

22. Moen IE, Nilsson K, Andersson A, Fagerland MW, Fluge G, Hollsing A, Gilljam M, Mared L, Pressler T, Santi H, Storrosten OT, Hjelte L. Dietary intake and nutritional status in a Scandinavian adult cystic fibrosis-population compared with recommandations. Food Nutr Res. 2011;55:7561.

23. Ledder O, Haller W, Couper RT, Lewindon P, Oliver M. Cystic fibrosis: an update for clinicians. Part 2: hepatobiliary and pancreatic manifestations. J Gastroenterol Hepatol. 2014;29(12):1954-62.
24. Laguna TA, Nathan BM, Moran A. Managing diabetes in cystic fibrosis. Diabetes Obes Metab. 2010;12(10):858-64.

25. Knapp EA, Fink AK, Goss CH, Sewall A, Ostrenga J, Dowd C, Elbert A, Petren KM, Marshall BC. The cystic fibrosis foundation patient registry. Design and methods of a national observational disease registry. Ann Am Thorac Soc. 2016;13(7):1173-9.

\section{Publisher's Note}

Springer Nature remains neutral with regard to jurisdictional claims in published maps and institutional affiliations.
Ready to submit your research? Choose BMC and benefit from:

- fast, convenient online submission

- thorough peer review by experienced researchers in your field

- rapid publication on acceptance

- support for research data, including large and complex data types

- gold Open Access which fosters wider collaboration and increased citations

- maximum visibility for your research: over 100M website views per year

At BMC, research is always in progress.

Learn more biomedcentral.com/submissions 